\section{GUESSINGS AT TRUTH}

I. $\mathrm{LD} \mathrm{SPENSER}_{\text {us }}^{\mathrm{LD}}$ in his wondrous Allegory, tells

$$
\text { " Could never :-" ") }
$$

We are constantly reminded that we must creep before we can walk. So that we cannot look coldly or sarcastically on

$$
\text { “. . . budding Grenius' earliest essàye," }
$$

provided always that we are sure of the earliness. For there often is a strange resemblance between the erratic first flights of the scientific fledgeling and the habitual evolutions of the time-hardened Paradoxer or of the Paper-Scientist.

Besides the mere dozen or so of really successful Physicists, all that the world seems able to produce at any one time, even in these later years, and whose efforts can at the best be rarely called more than Guesses, there is an untold multitude whose Guessings are irrepressible. These, unlike some at least of the former, never hide their light under a bushel. From week to week we view with curious awe the increasing piles of pamphlets under which our shelves and table sag, groan, and crack! Let us make an effort, and get rid of some of them. Not to the waste-basket - at least not at once - for there is something in almost every bundle of hay (in the Soudan it is not needles, but bricks and slag), and this is usually worth searching for, were it only in the interests of justice to those who have thus (unconsciously?) hidden them. We take the bundles as they come; many are rotten and can be tossed aside at once, others require more careful scrutiny.

The first we light upon is by our particularly modest contributor John O'Toole. ${ }^{1}$ [He does not seem to be aware of the powers of Peroxide of Hydrogen, which (though we did not proclaim the fact) enabled us on a former occasion easily to penetrate his incognito. But his secret is safe with us.] His present work is a singularly quaint protest against the modern abuse of elementary dynamical terms, and as such is well worthy of careful perusal. There can be little doubt that, of all physical subjects, as presented in an elementary form to the beginner, Dynamics is the most repulsive. And it stands at the very threshold. Mr. O'Toole shows the natural working of a clear, logical, mind in the middle of the present chaos. His pamphlet is one which should be read by all; for, though he hits all round and sometimes attacks the very giants of Science, he invariably hits fair as well as hard. It would take a whole article to discuss fully the questions he raises : suffice it to say that the root of the confusion which he so justly exposes is that little, but much-abused word Force; and to quote the following pregnant sentence as showing his point of view :-

"When w'e behold ... a group or sequence of phenomena, we insert force among them of ourselves, because we know from experience that if our organism were substituted for the acting or resisting body, we should have the sensation of pressure."

Next we take a couple of smaller, but more ambitious, pamphlets ${ }^{2}$ :-in each of which the Past, Present, and Future of the Universe are promptly settled, though the terms of settlement are by no means identical. When we find, however, that Herr Zehnder, in the second sentence of his pamphlet, says that insuperable objections can be raised against the hypotheses of Helmholtz as well as against those of Kant, Herschel, and Laplace, because they take too little account of the existing laws of mechanics, we begin to understand him; and we have

I Ausa Dynamica. Dublin: Hodges, Figgis, and Co., I884

a Ueber die Entwickelung des Weltalls und den Evigen Kreislauf der Materie. Von L. Zehnder. Basel, 1885.

On the Futzere of Life and the Universe, according to Science. Dundee: W. A. Drummond, 1883 . only to turn over a few pages to find him thoroughly revealed. His bugbear is the Dissipation of Energy:and he informs us that the "E.ternal Circulation of Matter" -in virtue of which all aggregations such as the sun will ultimately explode into their former nebulous condition, to recommence their condensation, \&c.,--is an immediate consequence of THE PRINCIPLE OF THE CONSERVATION OF LIGHT !

Our rival author sums up his Kreislauf as follows :-

"... life, matter, and all things, are the necessary and inevitable outcome of the existence of Space. Space or Room, in any form whatever, must of necessity be a form of force or energy, and all things are just phases or manifestations of the working of this force or energy ; the Earth is dissolving in Space like a lump of Salt in Water, but New Worlds are being formed in Suns ; this dissolving and forming process will go on for ever; and consequently life will be eternal ; . . ."

This is a step in advance even of Descartes, with whom Space and Matter were the same. We leave to the reader to judge which of the two has the more grotesquely grinned through the horse-collar, the German Swiss or the Scotsman.

Our next step is a large one, no less than from the Universe to the Atom. ${ }^{1}$ The work now before us is a very curious one. The author has hunted widely for his materials, and (very naturally) selects such only as suit his theory. So long as he can utilise Sir W. Thomson or Clerk-Maxwell he does so ; but, when he finds their statements incompatible with his theory, he has no difficulty in picking up what he wants from Zeuner, Rühlmann, Deschanel, \&c. He seems, however, not to be acquainted with the elaborate work of Athanase Dupré. This is unfortunate, for in it he would have found little difficulty in obtaining whatever he might require. The object of the essay, briefly stated, is to frame a theory of the liquid and solid states, somewhat on the lines of the kinetic gastheory:-only it seems we must have a mutual force between particles, whose law is something between the inverse $4^{\text {th }}$ and inverse $5^{\text {th }}$ powers of the distance. But somehow the law itself seems to vary with the distance; so that "we must apply the theory of probabilities to determine the potential at any centre due to the surrounding atoms." As a striking instance of Mr. Whiting's extensive range of quotation, we note that he refers, for the sum of a common series (given everywhere in elementary text-books of Trigonometry), to no less august an authority than Riemann in his Partielle Differentialgleichungen! We do not venture farther to criticise the work of a writer who can, as a matter of course, invoke such irresistible authorities.

We now come to a whole series of memoirs, tracts, letters, and pamphlets:-usually of American origin :-which deal specially with the vexed question of the Sun's temperature. From these we select one only, as the work of the most persistent, if not the most lucid or successful, of the many mere guessers on this subject. ${ }^{2}$ For the others consult Van Nostrand's Engineering Magazine, $\mathcal{E}_{0}$., passim. Something, if not very much, has been done in this matter in Europe. Pouillet, J. Herschel, Crova, Rosetti, Violle, and others have at all events gone to work in a scientific way:- though (as is obvious from the results of Prof. Langley recently given in our columns) the values obtained by them can be but very rough approximations. A few of Mr. Ericsson's weightier sayings will pretty well show the value and character of his treatise. At p. 58 we are told that

" . . . the actinometer merely shows the thermometric interval of solar intensity on Fahrenheit's scale, without reference to the position of that interval on a scale which commences at the accepted 'absolute zero.' I regard this absolute zero, however, as an ignis-fatuus, retreating as fast as we approach it."

I A New Theory of Cohesion, \&c. By Harold Whiting. (Cambridge, U.S., University Press, 1884.)

Solar Heat (an Extract from a work on "Radiant Heat"). By John 
The little kinematical, or rather quasi-corpuscular, excursus to which pp. 7I-74 are devoted, is one of the richest pieces of paradoxing (in De Morgan's sense) that we have ever met with. Here is a little bit of it :-

"Pouillet, having ascertained the number of thermal units imparted to the water in his pyrheliometer of $3^{\circ} 93$ ins. diameter, imagined that he had measured only the energy of the rays contained in a pencil of II'9 square inches section; whereas, in reality, he had, at the end of his experiment of five minutes' duration, subjected his instrument to the action of the entire number of rays contained in a passing pencil or sunbeam, the section of which we ascertain by multiplying the orbital advance of the earth during five minutes, $28,836,000 \mathrm{ft}$., by the diameter of the pyrheliometer, $0.305 \mathrm{ft}$."

Thus it is the number of rays, not the time of exposure to one ray, which determines the result!

One more quotation, a very short one, must be given. It is from p. 136 , and we put two words in italics:-

"In view of the fact that projectile force diminishes inversely as the square of the depth of the medium penetrated. . . ."

It is not easy to fix on the exact meaning of this very curious statement. Hence we must take it literally, whatever be the consequences. Discussion of penetration would obviously be useless in such a case, for the whole projectile force (even were it infinite) would be gone before penetration had commenced!

The immense expense which has been lavished on this volume, and on its truly wonderful illustrations, is calculated to produce reflections even more painful than those evoked by the perusal of the text itself. From the materials here given, something may yet be made, but certainly not on the lines chosen by the author.

We hope, shortly, to return to our store, and to select for the instruction and warning of our readers a few additional specimens, by no means inferior in quality to those just dealt with.

G. $\mathrm{H}$.

PROFESSOR FLEEMING $7 E N K I N$, LL.D., F.R.S.

$\mathrm{N}$ Friday last, most unexpectedly and greatly to the grief of all his friends, died Prof. Fleeming Jenkin at Edinburgh, at the age of fifty-two. He had been in somewhat delicate health for a considerable time, but was, as usual, personally directing the engineering operations in connection with telpherage in London and Sussex, and seemed to have greatly gained in health and strength when he started for Edinburgh some days before his death. But blood-poisoning succeeded a slight surgical operation, and his death rapidly followed.

He was born in Kent in I833, and was the son of the late Capt. Charles Jenkin, R.N. His school-days were spent at Jedburgh, Edinburgh, and Frankfort-on-theMaine, while he took his M.A. degree at the University of Genoa, and began his engineering career in Marseilles, thus acquiring a wide knowledge of languages and of peoples which was most valuable to him afterwards in his scientific and social life.

In $185 \mathrm{I}$ he returned to England, and was apprenticed to Messrs. Fairbairn's in Manchester, from which time his progress was rapid. We hope that the interesting and highly creditable history of his subsequent introduction as a well-trained mechanical engineer to submarine telegraphy (then in its extreme youth) and to Sir William Thomson, which led to his soon taking charge of the testing of the first Atlantic cable in 1858 , and to a friendship and partnership with Thomson and Varley, will yet be told by some one who can do full justice to it. Our grief at Varley's loss is yet fresh, and we deeply sympathise with Sir William Thomson at the close of this partnership, the existence of which has been synonymous with the progress of submarine telegraphy.

On the appointment of the Committee of the British Association on Electrical Standards Jenkin's scrvices were solicited, and the good work that he did as a member of this Committee is amply shown by his large contributions to the Reports on Electrical Standards, and which contain an account of his absolute measurement of the capacity of a condenser, the first such determination ever made ; and the chapters that he wrote in connection with these Reports on the subject of "Absolute Units" formed the only available text-book for the student of mathematical electricity before about the year 1872. Appended to these reports are the Cantor lectures which he delivered on the construction, laying, and testing of submarine cables, and these lectures showed as wide an acquaintance with the practice of electrical science as do the other chapters referred to with the theory of the subject.

In I 865 he was elected a Fellow of the Royal Society and Professor of Engineering in University College, London, and in I868 he became Professor in the University of Edinburgh, where he created a School of Engineering to which considerable numbers of prominent Engineers and Professors of Engineering acknowledge their indebtedness. In the following year the Royal Society of Edinburgh elected him a Fellow, and subsequently he became a Member of the Institution of Civil Engincers, having been made an Associate of that Institution as early as 1859 . In 1883 the honorary degree of LL.D. was conferred on him by the University of Glasgow. Jenkin's book on Electricity and Magnetism, published in 1873 , was a revelation to non-mathematical and even to many mathematical men, of the ideas which had until then been wrapped up in the mystery of mathematics or in the practice of the submarine cable testing-rooms. Sir William Thomson had been publishing many detached papers on electricity in the mathematical journals, and had been applying his knowledge in practice, so that an exact science of electrical quantities had been growing up among submarine cable engineers; but the electricity of the text-books remained as unscientific and primitive as of old : the knowledge of the practical men had become indeed far more scientific than the knowledge of the schools.

Fully recognising this, Prof. Jenkin made in his book a totally new departure, and presented electricity and magnetism for the first time in a text-book as subjects capable of quantitative study. To understand the great effect produced by this book, which has now passed through many editions, it must be remembered that neither Clerk-Maxwell's treatise, nor Thomson's reprint of his Mathematical Papers appeared until 1873 , and that at that time "electric potential," which to-day has its commercial unit, was to every one, except the engineers of submarine telegraphy, a mere mathematical function.

In 1882 a lecture was delivered at the Royal Institution on Electric Railways, and the system devised by Profs. Ayrton and Perry for effecting an absolute block, and thus enabling any number of electric trains to be run without the employment of drivers, guards, or signalmen, was described and exhibited by a working model. An account of this was read by Prof. Jenkin, and he at once saw that it contained the solution of a plan that he had been thinking oyer for doing on a large scale by electri. city what had previously been done on a small scale with pneumatic tubes. Telpherage, or the automatic electric transport of goods, was the outcome, and the development of practical methods of running carriers electrically along a steel rod suspended in the air from wooden posts, occupied him, with the other two inventors, during the last three years of his life, the system being one which needed new invention in every one of its details. His inventive power is described by his assistants as wonderfully active and prolific, and he had energetic characteristics which only seldom accompany inventive genius, and which made his cooperation invaluable to the other directors of the Telpherage Company. It is deeply to be regretted that, having busied himself so actively in the long series of telpherage experi- 